\title{
Anti-PRL-3 Monoclonal Antibody PRL3-
} zumab

National Cancer Institute

\section{Source}

National Cancer Institute. Anti-PRL-3 Monoclonal Antibody PRL3-zumab. NCI Thesaurus. Code C151931.

A humanized monoclonal antibody against phosphatase of regenerating liver 3 (PRL-3; PTP4A3), with potential immunomodulating and antineoplastic activities. Upon administration, anti-PRL-3 monoclonal antibody PRL3-zumab targets, binds to and blocks PRL-3 expressed on tumor cells. Although the exact mechanism of action through which this antibody kills tumor cells has yet to be fully elucidated, PRL3-zumab binds to PRL-3. This prevents PRL-3-mediated signaling in, inhibits the proliferation of and induces apoptosis in PRL-3-expressing tumor cells. PRL-3, a member of the PRL family of protein tyrosine kinases, is upregulated in a variety of tumor cells. Its expression is associated with increased invasiveness, higher metastatic potential, increased tumor cell survival and poor prognosis. 